\title{
Editorial: Social networks analyses in primates, a multilevel perspective
}

\author{
Ivan Puga-Gonzalez ${ }^{1} \cdot$ Sebastian Sosa ${ }^{2,3} \cdot$ Cédric Sueur $^{3}(0$
}

Received: 8 February 2019 / Accepted: 21 February 2019 / Published online: 21 March 2019

(c) Japan Monkey Centre and Springer Japan KK, part of Springer Nature 2019

Research using social network analyses has been booming since the start of the 2000s, with studies not only in humans but also many nonhuman species. Primates are no exception, with the number of retrievable items using the keywords "social networks primates" increasing tenfold from 2000 to 2017 (Fig. 1a). Studies are in various domains including psychology, behavioral sciences, and sociology, as well as neurosciences and infectious diseases (Fig. 1b). To our knowledge, several special issues and books have focused on animals (Croft et al. 2008; Whitehead 2008; Krause et al. 2009; Sheldon 2015; Sueur and Mery 2017) but with only one special issue devoted to primates (Sueur et al. 2011). In the last decade studies have evolved from describing structures (Manno 2008; Carter et al. 2013; Bret et al. 2013) and topologies of social networks or centrality of group members according to their sociodemographic characteristics (Lusseau and Newman 2004; Kanngiesser et al. 2011), to a more holistic approach where the function and evolution of networks are linked to ecological factors, behavioral mechanisms, network topologies, and vice versa (Brent et al. 2013; Fisher et al. 2016; Balasubramaniam et al. 2018). In this new special issue, our aim is to present this integrative and multilevel approach along with state-of-the-art methodologies and theoretical approaches for the study of primate social networks.

The three authors contributed equally to this special issue and this editorial.

Cédric Sueur

cedric.sueur@iphc.cnrs.fr

1 Institute for Religion, Philosophy and History, University of Agder, Kristiansand, Norway

2 School of Sociology and Anthropology, Sun Yat-sen University, Guangzhou 510275, China

3 Université de Strasbourg, CNRS, IPHC, UMR 7178, Strasbourg, France
Statistical techniques applied to social network analysis have greatly evolved in the last 10 years (Hoppitt and Laland 2013; Farine 2017; Finn et al. 2017; Sosa 2018). Papers in this issue show that whilst it is commonly accepted now to use permutation tests to avoid interdependence of social data (Koyama and Aureli 2018; Kawazoe and Sosa 2018, Rodrigues and Boeving 2018), new tools have emerged to study the social positions of individuals inside their network (i.e., egocentric network; Grampp et al. 2019), the multidimensional nature of networks (i.e., multiplex networks; Smith-Aguilar et al. 2018) and their dynamics (e.g., through ERGMs, exponential random graphs models; Lutz et al. 2019). Researchers are also increasingly using modeling to simulate social transmission of diseases or of information (based on network-based diffusion analysis, Wild and Hoppitt 2018) or to simulate network resilience through targeted deletion (Puga-Gonzalez et al. 2018).

These new tools allow a better understanding of the complexity of a network. Social relationships reflect the interplay of many types of interactions (e.g., grooming, aggression, proximity, genetic relatedness), and multiplex networks can give accurate information about the social position of group members, as shown by Smith-Aguilar et al. (2018) on wild spider monkey (Ateles geoffroyi).

The tools developed over the past decade also bring new possibilities for comparing species despite differences in group size or composition, as shown in the study by Lutz et al. (2019) on play network organization in three species (brown capuchins, Sapajus apella; hamadryas baboons, Papio hamadryas; diademed sifakas, Propithecus diadema). Network dynamics, referring to changes across time, seasons, or group composition, is also a vibrant topic given the availability of tools that can now tackle this problem. Papers in this issue include Xia et al.'s (2019) study of seasonal dynamics, especially the impact of reproductive season, on grooming networks in Tibetan macaques (Macaca thibetana), and Kawazoe and Sosa's (2018) analysis of how social 

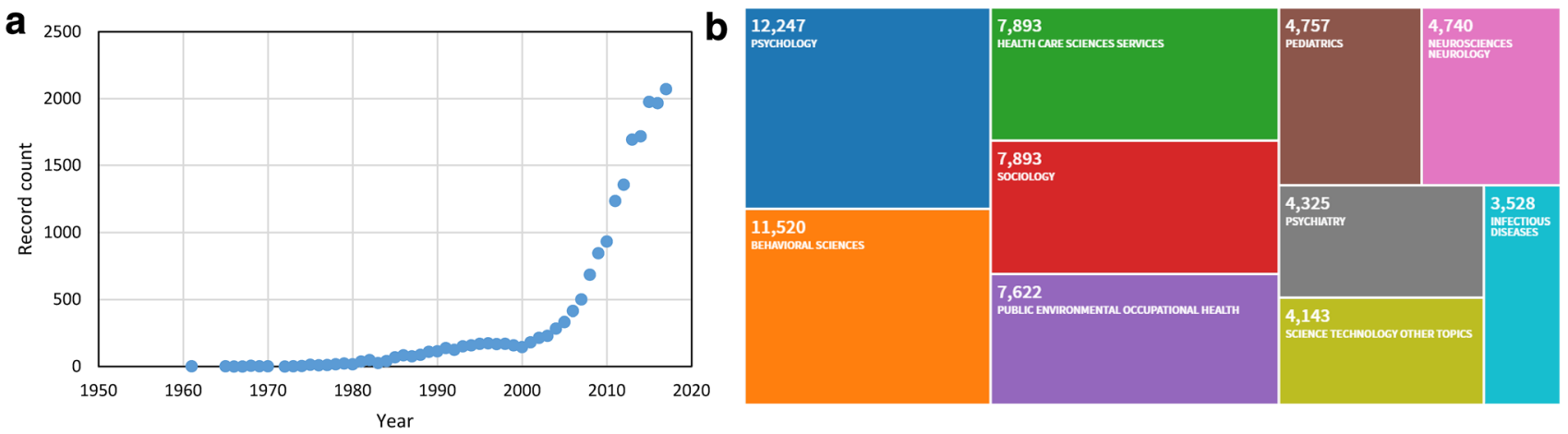

Fig. 1 Record count of the keywords "social networks primates" a per year and b per topic. Source: Web of knowledge

relationships affect male immigration and vice versa in Japanese macaques (Macaca fuscata). Finally, social network analysis is also a useful tool for applied ethology, as it can be used to assess how captive conditions and unnatural group compositions might influence the social relationships of group members, as reported by Koyama and Aureli (2018), and by Rodrigues and Boeving (2018) in chimpanzees and bonobos (Pan paniscus).

Network studies are not just a matter of topologies or dynamics but also of influence. We can study how network topologies influence different collective or social phenomena. Social learning is one of the most studied events linked to social network analysis. Network-based diffusion analysis or Markov chain models can be used to reveal which social characteristics (kinship, proximity, grooming, etc.) influence the social transmission of information. However, data on social interactions or associations are often incomplete (because we cannot observe every group member all the time), and uncertainty may lead to erroneous conclusions about which social characteristics influence information diffusion. Wild and Hoppitt (2018) extended network-based diffusion analysis to analyze the trade-off between including as many individuals as possible (regardless of individual's observation time) and having reliable data. This cutoff point maximizes the power of the analysis. Also, Grampp et al. (2019) observed how social biases influence social learning in juvenile vervet monkeys (Chlorocebus aethiops pygerythrus). Kinship emerged as the most important factor in social attention in juveniles, followed by dominance. The same approach was taken by Fratellone et al. (2018) to understand information transfer in collective decision-making, in a study of how social networks influence speed of collective movements when Tibetan macaques move together: because of their connectivity, females appear to favor decision efficiency.

Social transmission favors diffusion of not only information but also pathogens. In this special issue, Tiddi et al. (2019) assess whether parasite infection is better predicted by naturally occurring spatial networks (i.e., during natural observations) or by provisioning spatial networks (i.e., during experimental provisioning). In their study, network centrality increased during experiments, but this increase (closeness and betweenness) did not affect patterns of parasite infection. Puga-Gonzalez et al. (2018) found a contrary effect of centrality (in this case degree and eigenvector) on diffusion. Those authors simulated the deletion of targeted group members (with highest centrality) and randomly chosen group members, and found that network topology (e.g., modularity, diameter, efficiency) was affected more by the removal of central individuals. However, both tolerant (less aggressive) and intolerant (more aggressive) societies appeared to be robust to the loss of group members, even if more tolerant societies typically have more efficient networks.

This efficiency and robustness of networks may have important consequences for fitness of group members. This raises the question of the evolution of networks, with some topologies favoring the transmission of information and decreasing epidemics. Sueur et al. (2018) discuss how evolutionary driving forces (genetic and cultural) may result in different individual social strategies, which might produce network topologies optimized to specific socioecological conditions. The authors use the term "collective social niche construction" when referring to these evolutionary processes driving network structures.

In conclusion, this special issue introduces new results and methodologies, but more importantly, it delivers new perspectives and concepts that we hope will be beneficial to researchers in the future.

\section{References}

Balasubramaniam KN, Beisner BA, Berman CM et al (2018) The influence of phylogeny, social style, and sociodemographic factors on macaque social network structure. Am J Primatol 80:e22727 
Brent LJN, Heilbronner SR, Horvath JE et al (2013) Genetic origins of social networks in rhesus macaques. Sci Rep. https://doi. org/10.1038/srep01042

Bret C, Sueur C, Ngoubangoye B et al (2013) Social structure of a semi-free ranging group of Mandrills (Mandrillus sphinx): a social network analysis. PLoS ONE 8:e83015. https://doi.org/10.1371/ journal.pone.0083015

Carter KD, Brand R, Carter JK et al (2013) Social networks, long-term associations and age-related sociability of wild giraffes. Anim Behav 86:901-910. https://doi.org/10.1016/j.anbehav.2013.08.002

Croft DP, James R, Krause DJ (2008) Exploring animal social networks. Princeton University Press, Princeton

Farine DR (2017) A guide to null models for animal social network analysis. Methods Ecol Evol 8:1309-1320

Finn KR, Silk MJ, Porter MA, Pinter-Wollman N (2017) Novel insights into animal sociality from multilayer networks. arXiv: 171201790

Fisher DN, Rodríguez-Muñoz R, Tregenza T (2016) Wild cricket social networks show stability across generations. BMC Evol Biol 16:151

Fratellone GP, Li JH, Sheeran LK et al (2018) Social connectivity among female Tibetan macaques (Macaca thibetana) increases the speed of collective movements. Primate. https://doi.org/10.1007/ s10329-018-0691-6

Grampp M, Sueur C, van de Waal E, Botting J (2019) Social attention biases in juvenile wild vervet monkeys; implications for socialisation and social learning processes. Primates. https://doi. org/10.1007/s10329-019-00721-4

Hoppitt W, Laland KN (2013) Social learning: an introduction to mechanisms, methods, and models. Princeton University Press, Princeton

Kanngiesser P, Sueur C, Riedl K et al (2011) Grooming network cohesion and the role of individuals in a captive chimpanzee group. Am J Primatol 73:758-767. https://doi.org/10.1002/ajp.20914

Kawazoe T, Sosa S (2018) Social networks predict immigration success in wild Japanese macaques. Primates. https://doi.org/10.1007/ s10329-018-0702-7

Koyama NF, Aureli F (2018) Social network changes during space restriction in zoo chimpanzees. Primates. https://doi.org/10.1007/ s10329-018-0675-6

Krause J, Lusseau D, James R (2009) Animal social networks: an introduction. Behav Ecol Sociobiol 63:967-973. https://doi. org/10.1007/s00265-009-0747-0

Lusseau D, Newman MEJ (2004) Identifying the role that animals play in their social networks. Proc R Soc B Biol Sci 271:S477-S481. https://doi.org/10.1098/rsbl.2004.0225

Lutz MC, Ratsimbazafy J, Judge PG (2019) Use of social network models to understand play partner choice strategies in three primate species. Primate. https://doi.org/10.1007/s10329-018-00708 $-7$
Manno TG (2008) Social networking in the Columbian ground squirrel, Spermophilus columbianus. Anim Behav 75:1221-1228. https:// doi.org/10.1016/j.anbehav.2007.09.025

Puga-Gonzalez I, Sosa S, Sueur C (2018) Social style and resilience of macaques' networks, a theoretical investigation. Primate. https:// doi.org/10.1007/s10329-018-0684-5

Rodrigues MA, Boeving ER (2018) Comparative social grooming networks in captive chimpanzees and bonobos. Primate. https://doi. org/10.1007/s10329-018-0670-y

Sheldon BC (2015) Virtual issue: social network analysis. J Anim Ecol. http://www.journalofanimalecology.org/view/0/VI_social_netwo rk_analysis.html. Accessed 23 Nov 2018

Smith-Aguilar SE, Aureli F, Busia L et al (2018) Using multiplex networks to capture the multidimensional nature of social structure. Primate. https://doi.org/10.1007/s10329-018-0686-3

Sosa S (2018) Social network analysis. In: Vonk J, Shackelford T (eds) Encyclopedia of animal cognition and behavior. Springer, Cham

Sueur C, Mery F (2017) Editorial: Social interaction in animals: linking experimental approach and social network analysis. Front Psychol. https://doi.org/10.3389/fpsyg.2017.00035

Sueur C, Jacobs A, Amblard F et al (2011) How can social network analysis improve the study of primate behavior? Am J Primatol 73:703-719

Sueur C, Romano V, Sosa S et al (2018) Mechanisms of network evolution: a focus on socioecological factors, intermediary mechanisms, and selection pressures. Primates. https://doi.org/10.1007/s1032 9-018-0682-7

Tiddi B, Pfoh R, Agostini I (2019) The impact of food provisioning on parasite infection in wild black capuchin monkeys: a network approach. Primates. https://doi.org/10.1007/s10329-018-00711-y

Whitehead H (2008) Analyzing animal societies: quantitative methods for vertebrate social analysis. University of Chicago Press, Chicago

Wild S, Hoppitt W (2018) Choosing a sensible cut-off point: assessing the impact of uncertainty in a social network on the performance of NBDA. Primates. https://doi.org/10.1007/s10329-018-0693-4

Xia DP, Kyes RC, Wang X et al (2019) Grooming networks reveal intra- and intersexual social relationships in Macaca thibetana. Primates. https://doi.org/10.1007/s10329-018-00707-8

Publisher's Note Springer Nature remains neutral with regard to jurisdictional claims in published maps and institutional affiliations. 